\title{
8 - Building insulation materials based on agricultural wastes
}

\author{
Author links open overlay panel \\ FlorindoGaspar $^{1}$ \\ AliaksandrBakatovich ${ }^{2}$ \\ NadezhdaDavydenko ${ }^{2}$ \\ ArpanJoshi $^{3}$
}

https://doi.org/10.1016/B978-0-12-819481-2.00008-8Get rights and content

\section{Abstract}

Ecological insulation materials of vegetable raw materials are increasingly widespread. The agricultural wastes can have an interesting role because their use allows the revaluation of agricultural wastes, whose disposal is a serious issue.

This chapter gives an overview about the use of agricultural wastes on insulating materials. The source and characteristics of various types of wastes are described. The manufacturing processes considering the types of binders, including the main parameters involved, are explained. An overview is given about the properties of the insulation materials, including thermal conductibility, density, mechanical strength, hygroscopic behavior, acoustic and fire performances, and environmental performance. Suggestions regarding the future research needs are also presented.

- Previous chapter in book

- Next chapter in book

\section{Keywords}

Building materials agricultural wastes insulating materials thermal conductivity 
sound absorption

fire performance

environmental performance 